\title{
Studienergebnisse
}

\section{Monoklonaler Antikörper hilft bei Migräne}

Mit einem neuen humanen monoklonalen Antikörper könnte demnächst ein weiterer spezifischer Wirkstoff zur Vorbeugung von Migräne-Attacken zur Verfügung stehen.

Ein neuer monoklonaler Antikörper zur Migräne-Prophylaxe bei episodischer und chronischer Migräne hilft diesen schwerstbetroffenen MigränePatienten. Ferner hilft der monoklonale Antikörper Migräne-Patienten, die gegen akute Migräne-Attacken zu viele Medikamente einnehmen. Menschen, die unter chronischer Migräne leiden, sind dem weitgehend hilflos ausgeliefert.

Bisher sind nur das Antiepileptikum Topiramat und Botulinumtoxin A (Botox) für die Behandlung von Patienten mit chronischer Migräne und Schmerzmittelübergebrauch zugelassen, hieß es in einer Aussendung zum EAN-Kongress. Mit großem Interesse verfolgten Neurologen und andere Schmerzspezialisten daher die Entwicklung des Wirkstoffs Erenumab, der in Studien bei episodischer Migräne bereits vielversprechende Ergebnisse geliefert hat.

Dieser vollständig humane monoklonale Antikörper richtet sich gegen den sogenannten Calcitonin-Gene-Related-Peptid(CGRP)-Rezeptor, der im Verdacht steht, an der Übertragung der schmerzhaften Migräne-Signale beteiligt zu sein. In einer im Vorjahr durchgeführten Phase II-Studie konnte bei Patienten mit chronischer Migräne, die im Mittel unter 18 Migränetagen pro Monat litten, eine Reduktion um durchschnittlich 6,6-Tage pro Monat erreicht werden. In der Plazebogruppe war es zu durchschnittlich um 4,2 Tage geringeren Belastung mit Migräne gekommen. In zwei Phase III-Studien konnte die Wirksamkeit bestätigt werden.

In Amsterdam legte ein internationales Forscherteam nun eine Subanalyse der Phase II-Studie vor. Die in Deutschland, Dänemark und den USA tätigen Neurologen untersuchten, ob der Antikörper auch bei Migräni-

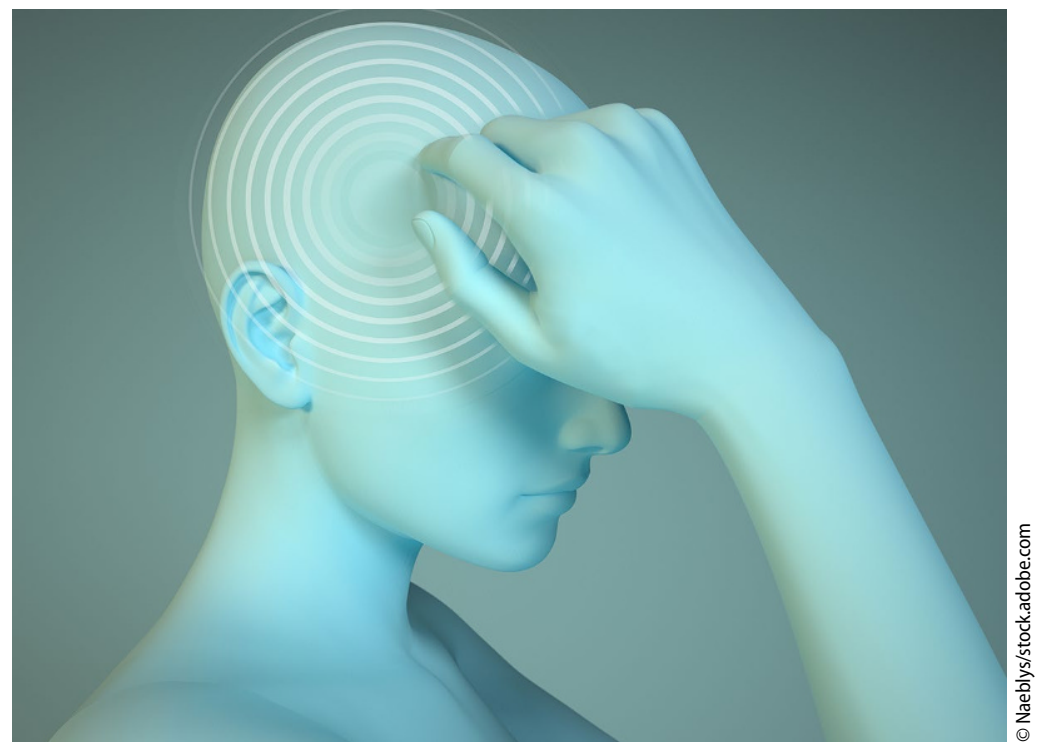

॥ Neuer Antikörper konnte in einer Phase-III-Studie die Zahl der Migränetage reduzieren

kern mit Schmerzmittelübergebrauch Wirkung zeigt, die vor Studienbeginn zur Bekämpfung ihrer akuten Migräne mehr als die verträgliche Dosis an Medikamenten eingenommen hatten. Eingeteilt waren die Teilnehmer in drei Gruppen: Die erste Gruppe erhielt ein Placebo, die zweite 70 Milligramm Erenumab und die dritte 140 Milligramm des Antikörpers. Im Schnitt litten sie zwischen 18,8 und 19,6 Tagen pro Monat unter Migräneattacken.

\section{Mehr schmerzfreie Tage}

„Unsere Auswertung zeigt, dass Erenumab die Zahl der Migränetage bei Patienten mit Medikamenten-Übergebrauch genauso effizient reduziert wie im Gesamtkollektiv", fasste der Neurologe Hans-Christoph Diener von der Medizinischen Fakultät der Universität Duisburg-Essen die Ergebnisse zusammen. Unabhängig von der Dosis profitierten die mit Erenumab versorgten Patienten im Schnitt mit 6,6 mehr schmerzfreien Tagen pro Monat, in der Plazebogruppe reduzierten sich die Migränetage dagegen nur um 3,5 Tage. Während die Anfallshäufigkeit in den Erenumab-Gruppen bei mehr als einem Drittel der Teilnehmer (35 bzw. 36\%) um die Hälfte oder mehr abnahm, war das in der Plazebogruppe bei nicht einmal einem Fünftel (18\%) der Fall.

Ebenso deutlich fiel auch der Vergleich über die eingesparten Medikamente aus:Während Patienten mit Erenumab an 5,4 bzw. 4,9 Tagen öfter als davor auf die Einnahme zusätzlicher migränespezifischer Mittel verzichten konnten, kamen die Plazebobehandelten nur an 2,1 zusätzlichen Tagen ohne diese aus.

psychopraxis. neuropraxis $2017 \cdot 20: 233$ https://doi.org/10.1007/s00739-0170424-4

๑) Springer-Verlag GmbH Austria 2017
Quelle: APA/B \& K Kommunikationsberatung $\mathrm{GmbH}$ 